\title{
ARTICLE
}

Acute lymphoblastic leukemia

\section{Twins with different personalities: STAT5B — but not STAT5A—has a key role in BCR/ABL-induced leukemia}

\author{
Sebastian Kollmann ${ }^{1} \cdot$ Eva Grundschober ${ }^{1} \cdot$ Barbara Maurer $^{1} \cdot$ Wolfgang Warsch $^{1} \cdot$ Reinhard Grausenburger $^{1}$. \\ Leo Edlinger ${ }^{1}$. Jani Huuhtanen ${ }^{2} \cdot$ Sabine Lagger $^{3} \cdot$ Lothar Hennighausen $^{4} \cdot$ Peter Valent $^{5,6} \cdot$ Thomas Decker $^{7}{ }^{7}$. \\ Birgit Strobl $^{8} \cdot$ Mathias Mueller $^{8} \cdot$ Satu Mustjoki $\mathbb{D}^{2} \cdot$ Andrea Hoelbl-Kovacic $^{1} \cdot$ Veronika Sexl $^{1}$
}

Received: 5 June 2018 / Revised: 3 October 2018 / Accepted: 3 December 2018 / Published online: 24 January 2019

(c) The Author(s) 2019. This article is published with open access

\begin{abstract}
Deregulation of the Janus kinase/signal transducers and activators of transcription (JAK/STAT) signaling pathway is found in cancer with STAT5A/B controlling leukemic cell survival and disease progression. As mutations in STAT5B, but not STAT5A, have been frequently described in hematopoietic tumors, we used BCR/ABL as model systems to investigate the contribution of STAT5A or STAT5B for leukemogenesis. The absence of STAT5A decreased cell survival and colony formation. Even more drastic effects were observed in the absence of STAT5B. STAT5B-deficient cells formed BCR/ABL ${ }^{+}$ colonies or stable cell lines at low frequency. The rarely evolving Stat $5 b^{-/-}$cell lines expressed enhanced levels of BCR/ ABL oncoprotein compared to wild-type cells. In line, Stat $5 b^{-/-}$leukemic cells induced leukemia with a significantly prolonged disease onset, whereas Stat $5 a^{-/-}$cells rapidly caused a fatal disease superimposable to wild-type cells. RNA-sequencing (RNA-seq) profiling revealed a marked enhancement of interferon (IFN)- $\alpha$ and IFN- $\gamma$ signatures in Stat $5 b^{-/-}$cells. Inhibition of IFN responses rescued $\mathrm{BCR} \mathrm{ABL}^{+}$colony formation of Stat $5 b^{-/-}$-deficient cells. A downregulated IFN response was also observed in patients suffering from leukemia carrying STAT5B mutations. Our data define STAT5B as major STAT5 isoform driving BCR/ABL ${ }^{+}$leukemia. STAT5B enables transformation by suppressing IFN- $\alpha / \gamma$, thereby facilitating leukemogenesis. Our findings might help explain the high frequency of STAT5B mutations in hematopoietic tumors.
\end{abstract}

These authors contributed equally: Sebastian Kollmann, Eva Grundschober, Barbara Maurer

Shared last authorship: Andrea Hoelbl-Kovacic, Veronika Sexl

Supplementary information The online version of this article (https:// doi.org/10.1038/s41375-018-0369-5) contains supplementary material, which is available to authorized users.

Veronika Sexl

veronika.sexl@vetmeduni.ac.at

1 Institute of Pharmacology and Toxicology, University of Veterinary Medicine Vienna, 1210 Vienna, Austria

2 Hematology Research Unit Helsinki, Department of Clinical Chemistry and Hematology, University of Helsinki and Helsinki University Hospital Comprehensive Cancer Center, P.O. Box 700, 00290 Helsinki, Finland

3 Unit of Laboratory Animal Pathology, University of Veterinary Medicine Vienna, 1210 Vienna, Austria

4 Laboratory of Genetics and Physiology, National Institute of Diabetes and Digestive and Kidney Diseases, National Institutes of

\section{Introduction}

Janus kinase/signal transducers and activators of transcription (JAK/STAT) signaling has been implicated in multiple forms of solid as well as hematologic cancers [1]. In particular, the constitutive activation of JAK/STAT signaling is found in several forms of leukemia [2-7]

Health, Bethesda, MD 20892, USA

5 Department of Internal Medicine I, Division of Hematology and Hemostaseology, Comprehensive Cancer Center, Medical University of Vienna, 1090 Vienna, Austria

6 Ludwig Boltzmann Cluster Oncology, Medical University of Vienna, 1090 Vienna, Austria

7 Max F. Perutz Laboratories (MFPL), University of Vienna, 1030 Vienna, Austria

8 Department for Biomedical Sciences Institute of Animal Breeding and Genetics, University of Veterinary Medicine Vienna, 1210 Vienna, Austria 
(http://cancergenome.nih.gov/). We have identified the transcription factors STAT5A/B as critical nodes in the signaling network downstream of the leukemia-associated BCR/ABL oncogene [8, 9]. The STAT5 locus is comprised of two genes, STAT5A and STAT5B. So far, only little is known of STAT5A- or STAT5B-specific functions in hematopoietic cells. In non-hematopoietic cells, STAT5A and STAT5B fulfill non-redundant functions. STAT5A, but not STAT5B, is essential for mammary gland development and prolactin signaling $[10,11]$. On the other hand, STAT5B mediates growth hormone signaling and Stat5bknockout mice show reduced body growth [12, 13]. In BCR/ABL-driven lymphoid as well as myeloid leukemia, the combined loss of STAT5A and STAT5B halts disease, the requirement for STAT5A/B extending to the leukemic stem cell compartment [9].

In leukemia, STAT5A and STAT5B may have individual functions as the constitutive activation of either protein is capable to inflict a disease of a specific phenotype. In mice, the expression of a constitutively active (ca) version of STAT5A (caSTAT5A) induces an aggressive multi-lineage leukemia [14]. The expression of caSTAT5B or the overexpression of wild-type (wt) STAT5B selectively disturbs lymphopoiesis resulting in profound expansion of $\mathrm{B}$ and $\mathrm{T}$ cell numbers [15-17]. In NPM-ALK-driven neoplasms, silencing of STAT5B blocks and silencing of STAT5A supports the disease $[18,19]$. So far it remains unclear how STAT5A and STAT5B exert their independent functions despite sharing $94 \%$ structural homology. Complete Stat5a and Stat $5 b$ single knockout mice were generated which offer the possibility to dissect individual functions of these proteins $[10,13]$.

Genome-wide screening of mutations in cancers revealed that mutations affect $S T A T 5 B$ at a much higher frequency than STAT5A (https://cancer.sanger.ac.uk/cosmic). These mutations are confined to hematological disorders (mainly $\mathrm{T}$ cell and natural killer $\mathrm{T}$ cell leukemias and lymphomas).

In 2013, Rajala et al. [20] identified a STAT5B missense mutation (encoding a STAT5B ${ }^{\mathrm{N} 642 \mathrm{H}}$ mutant) in cases of large granulocytic lymphocytic (LGL) leukemia. The same mutation was later on also discovered in acute $\mathrm{T}$ cell leukemia [21, 22], T-prolymphocytic leukemia [23], and hepatosplenic T cell lymphoma [24]. By now, according to the COSMIC database, somatic STAT5B ${ }^{\mathrm{N} 642 \mathrm{H}}$ mutation was identified in 11 types of leukemia currently summing up to prevalence in more than 90 patients, the incidence rising (cancer.sanger.ac.uk/cosmic/).

The STAT5B ${ }^{\mathrm{N} 642 \mathrm{H}}$ mutation affects the Src homology 2 domain and reportedly increases the stability of the STAT5B dimer [25]. As a result, the transcriptional activity of STAT5B is markedly increased [21]. In line, the presence of a STAT5B ${ }^{\mathrm{N} 642 \mathrm{H}}$ mutant in $\mathrm{BA} / \mathrm{F} 3$ cells confers interleukin-3-independent growth [26, 27]. Only recently, a
STAT5 $^{\mathrm{N} 642 \mathrm{H}}$ transgenic mouse model was generated recapitulating the $\mathrm{T}$ cell neoplasia phenotype observed in human patients [27]. These observations indicate a yet underestimated role of STAT5B in human and murine leukemogenesis.

Here we investigated why mutations in human cancers are predominantly found in STAT5B and not in STAT5A. We used knockout mice, which either lack STAT5A or STAT5B [10, 13]. Using a combination of transformation studies in vitro and in vivo, we identify STAT5B as the dominant isoform allowing leukemic cell transformation and propagation of disease. Transcriptional profiling revealed that IFN- $\alpha$ and IFN- $\gamma$ pathways are pronouncedly upregulated in Stat5a $a^{-/-}$and Stat $5 b^{-/-}$cells, the extent being higher in Stat $5 b^{-/-}$cells. Blockage of IFN- $\alpha$ and IFN$\gamma$ signaling restored their capability to transform. In line, transcriptional analysis of $S T A T 5 B$-mutated leukemia patient samples revealed a downregulated IFN response. Taken together, our data point at a dominant role of STAT5B in suppressing IFN- $\alpha$ and IFN- $\gamma$ signaling during leukemic transformation.

\section{Material and methods}

\section{Primary CML patient samples}

Primary leukemic cells were obtained from patients with chronic myeloid leukemia (CML) at routine blood and bone marrow (BM) examinations after informed consent was given in compliance with the Declaration of Helsinki. Peripheral blood and BM mononuclear cells were isolated using Ficoll. Samples were analyzed for BCR/ABL mutations and BCR/ABL messenger RNA (mRNA) levels according to the international scale as reported [28]. Use of human samples was approved by the ethics committee of the Medical University of Vienna (ethics committee no. 1184/2014) and is in compliance with Austrian legislation.

\section{Primary T-LGLL patient samples}

The study was undertaken in compliance with the principles of the Declaration of Helsinki and was approved by the ethics committees in the Helsinki University Central Hospital (Helsinki, Finland). All patients and healthy controls gave written informed consents. All patients met the criteria of T-cell large granular lymphocytic leukemia (T-LGLL) as defined by the World Health Organization (2008). STAT5B mutations were identified with exome sequencing and validated by capillary sequencing, as previously described [20, 29, 30]. Patient samples harboring the following mutations were included in this study: STAT5B ${ }^{\text {Y665F }}$, STAT5B $^{\text {Q706L }}$, and STAT5B ${ }^{\mathrm{S} 715 \mathrm{~F}}$. 


\section{Mice}

$\mathrm{Stat}_{5 a^{-/-}}$[10], Stat5 $b^{-/-}$[13], NSG (NOD.Cg-Prkdc ${ }^{\text {scid }}$ Il2 $\mathrm{rgtm}{ }^{1 W j l} / \mathrm{SzJ}$; license BMWF 68.205/0093-WF/V/3b/ 2015), and NOG-F mice (NOD.Cg-Prkdcscid Il2rgtmlSug/ JicTac, Taconic Biosciences A/S) were maintained under SPF conditions at the University of Veterinary Medicine Vienna. All animal experiments were conducted in 6- to 9-week-old mice and approved by institutional ethics and animal welfare committee and the national authority according to $\S \S 26 \mathrm{ff}$. of Animal Experiments Act, Tierversuchsgesetz 2012 - TVG 2012 (license BMWF-68.205/0218-II/3b/2012).

\section{Transplantation of leukemic cells and new-born infections}

\section{Subcutaneous injection}

NSG mice were injected into the flanks with $1 \times 10^{6} \mathrm{BCR} /$ $\mathrm{ABL}^{\mathrm{p} 185+}$ cells. After 8-12 days, tumor nodules were palpable and tumor sizes were measured every other day with a slide caliper and calculated using the formula: $a \times b / 2$ ( $a$ : length of tumor; $b$ : tumor width). Tumor weights were determined after sacrificing the mice.

\section{Intravenous injection}

$\mathrm{BCR} / \mathrm{ABL}^{\mathrm{p} 185+}$ cells $\left(1 \times 10^{4}\right)$ were injected intravenously (i.v.) into NSG mice. Sick mice were sacrificed upon paralysis of hind legs and analyzed for spleen weights, white blood cell counts, and the presence of leukemic cells in BM, spleen, and blood.

BCR/ABL ${ }^{185+}$ cells $\left(5 \times 10^{4}\right)$ were injected i.v. into NOG-F mice. Mice were sacrificed at day 5, day 8 , and day 11 upon injection and analyzed for the presence of leukemic cells in BM, spleen, and blood.

\section{New-born infections}

Ab-MulV was subcutaneously injected into new-born mice (24-48 h after birth), conducted as described [31].

\section{RNA-seq analysis}

\section{Murine data}

For RNA-sequencing (RNA-seq) of immortalized Stat $5 a^{-/-}$, Stat $5 b^{-1-}$, and wt BCR/ABL ${ }^{\mathrm{p} 185+}$ cell lines, libraries from mRNA of these cell lines $(n=1$ per genotype in three technical replicates) were prepared using the Lexogen SENSE mRNA-Seq library preparation kit (Lexogen, Vienna, Austria). Single-end, 50 bp sequencing was performed on an Illumina HiSeq-2500 sequencer
(Illumina, San Diego, CA, USA). After quality control of raw data with FastQC and removement of adapters and lowquality reads with Trimmomatic (version 0.36), reads were mapped to the GENECODE M13 genome using STAR (version 2.5.2b) with default parameters. Counts for union gene models were obtained using featureCounts from the Subread package (version 1.5.1). Differentially expressed (Benjamin-Hochbert corrected $p$ value ( $p$-adjust) $<0.05$ and fold change $>2$ ) genes were identified using DESeq2 (version 1.18.1). Genset enrichment analysis (GSEA) against Molecular Signature Database (MSigDB) hallmark gene sets with $\log 2$ fold-change ranked lists from differential expression analysis (DEA) was utilized to determine significantly deregulated pathways (absolute normalized enrichment score (NES) $>1$, false discovery rate (FDR) $<0.25$ ). To demonstrate stronger increase of the type I and type II IFN response pathway in Stat5 $b^{-/-}$than in Stat5a $a^{-/-}$ BCR/ABL ${ }^{\mathrm{p} 185+}$ cell lines, $\log 2$ fold changes and adjusted $p$ values of the DEA (Stat5a $a^{-1-}$ vs. wt and Stat $5 b^{-1-}$ vs. wt) of genes that contribute to core enrichment in either of the two GSEA analysis are shown.

The RNA-seq data reported in this article have been deposited in the Gene Expression Omnibus database (Accession ID: GSE121246).

\section{Human patient data}

For RNA-seq of STAT5B mutant $\left(1 \mathrm{CD} 4^{+}, 1 \mathrm{CD} 4^{+} \mathrm{CD} 8^{+}\right.$, and $\left.2 \mathrm{CD}^{+}\right)$and wt $\left(13 \mathrm{CD} 8^{+}\right)$T-LGLL samples were prepared using miRNeasy mini kit (Qiagen) and Nucleospin RNA II kit (Macherey-Nagel). Sequencing libraries were sequenced using paired-end $100 \mathrm{bp}$ read format on an Illumina HiSeq 2000 instrument (Illumina). Paired-end reads passing the pre-processing were aligned to human reference genome build 38 (EnsEMBL v82) using STAR (version 2.5.2b) with the default two-pass per-sample mapping settings. Reads were then sorted by coordinate using the SortSAM and PCR duplicates were marked using the MarkDuplicate module of the Picard toolkit. Mapped reads were assigned to gene features (EnsEMBL v82) using FeatureCounts by allowing multi-mapping reads and assignment of a read to more than one overlapping feature.

Differentially expressed ( $p$-adjust $<0.05$ and fold change $>2$ ) genes were identified with edgeR (version 3.22.3) with common dispersion with default parameters. GSEA analysis was done as described above.

\section{Colony formation assay with or without blocking of IFN- $\alpha / \beta$ and IFN- $\gamma$ responses and growth curve}

$\mathrm{BM}$ cells were infected with $\mathrm{Ab}-\mathrm{MulV}, \mathrm{BCR} / \mathrm{ABL}^{\mathrm{p} 185}$, or $\mathrm{BCR} / \mathrm{ABL}^{\mathrm{p} 210}$ virus containing supernatant as previously described [8]. Cells $\left(1 \times 10^{6}\right)$ were seeded in methylcellulose 
without supplement of cytokines (MethoCult, 03231, STEMCELL Technologies, Vancouver, BC, Canada). For IFN signaling blocking experiments, $10 \mu \mathrm{g} / \mathrm{ml}$ immunoglobulin G (IgG) control antibody (02-6102, Invitrogen, San Diego, CA, USA) or $10 \mu \mathrm{g} / \mathrm{ml}$ IFNAR1-blocking antibody (eBioscience, San Diego, CA, USA) or $10 \mu \mathrm{g} / \mathrm{ml}$ IFN- $\gamma$-blocking antibody (Becton-Dickinson, Franklin Lakes, NJ, USA) or a combination of both (in total $10 \mu \mathrm{g} / \mathrm{ml}$ ) was directly added to the methylcellulose (MethoCult, 03231, STEMCELL Technologies). Colonies were counted after 9-14 days and photographed using a ChemiDoc ${ }^{\mathrm{TM}}$ Touch Imaging System (Bio-Rad, Hercules, CA, USA). Representative colonies were picked for fluorescence-activated cell sorting (FACS) analysis.

For growth analysis, $5 \times 10^{5} \mathrm{BCR} / \mathrm{ABL}^{\mathrm{p} 185+}$ cells were seeded and $100 \mu \mathrm{l}$ of cell suspension was used for counting via flow cytometry at indicated time points. Cells were split every third day and filled up with fresh medium to maintain exponential growth.

Competitive growth analysis of short hairpin RNA (shRNA)-mediated STAT5A and STAT5B knockdowns was performed in K562 cells. Percentages of green fluorescent protein-positive $\left(\mathrm{GFP}^{+}\right)$cells (starting point/starting value in all samples $\sim 80 \% \mathrm{GFP}^{+}$) were analyzed at the indicated time points via flow cytometry. All time points were normalized to the percentage of $\mathrm{GFP}^{+}$cells at day 5 of the respective sample. Cells were split every third day and filled up with fresh medium to maintain exponential growth.

\section{Statistical analyses}

Kruskal-Wallis test (followed by Dunn's test), one-way analysis of variance (followed by Tukey's multiple comparison test), log-rank (Mantel-Cox) test, Wilcoxon-MannWhitney test, $\chi^{2}$ test and assessment of half maximal inhibitory concentration $\left(\mathrm{IC}_{50}\right)$ values were performed using GraphPad Prism ${ }^{\circ}$ Software version 5.04 and 6.02. Statistical significance is indicated for each experiment specifically $(* p<0.05 ; * * p<0.01 ; * * * p<0.001)$.

\section{Results}

\section{Overexpression of Stat5b enhances cell proliferation of $\mathrm{BCR} / \mathrm{ABL}^{+}$cells}

We have shown that the levels of STAT5A increase during progression of CML [32]. Similarly, the expression of STAT5B increases significantly in samples derived from CML patients when they reach the accelerated phase (AP) or chronic phase (CP). We observe a tendency of STAT5B upregulation in samples derived from patients in blast crisis and in those who became imatinib-resistant during $\mathrm{CP}$ (Fig. 1a). To test whether STAT5A or STAT5B control survival of $\mathrm{BCR} / \mathrm{ABL}^{+}$leukemic cells, we expressed Stat5a, Stat5b, or the empty vector (henceforth called "GFP" for simplicity) in $v$-Abl-transformed cells. Enforced expression of STAT5A or STAT5B provided a proliferative advantage, the effect of STAT5B overexpression being more pronounced (Supplementary Figure 1a). Loss-offunction studies in murine $\mathrm{BCR} / \mathrm{ABL}^{\mathrm{p} 185+}$ cells complemented these experiments; knockdown of Stat $5 b$ induced apoptosis, whereas the effects of the Stat5a-directed shRNA were less pronounced shortly upon sorting of infected cells (Fig. 1b). To understand the effect of STAT5A and STAT5B on the initial transformation process, we infected $\mathrm{BM}$ cells with a retrovirus encoding for $v-A b l$ in combination with a retrovirus conferring either Stat $5 a$ or Stat $5 b$ expression linked via internal ribosome entry site to GFP. Mean levels of expression per cell of either vector were superimposable (Supplementary Figure 1b). Again, the empty GFP vector served as control. Against our expectations, the concomitant expression of Stat5a and the $v-A b l$ oncogene repressed colony formation compared to the empty vector setting (Fig. 1c). In contrast, the frequency of colonies expressing both $\mathrm{v}-\mathrm{Abl}$ and STAT5B was increased.

\section{Stat $5 b$ promotes initial transformation and cell proliferation}

To substantiate the findings, we next employed mouse models with specific deletions for either STAT5A or STAT5B $[10,13]$. BM cells were infected with a retrovirus encoding $\mathrm{BCR} / \mathrm{ABL}^{\mathrm{p} 185}$ and plated in growth factor-free methylcellulose. Whereas the absence of Stat5a reduced colony numbers about two-thirds, hardly any colonies were derived from Stat5b-deficient BM (Fig. 2a). These differences were reflected by the frequency in the outgrowth of stable cell lines; in the absence of STAT5A, we received 10/ 17 stable (59\%) cell lines, while only 4/14 (29\%) stable cell lines were derived from STAT5B-deficient BM $\left(\chi^{2}: 94.75\right.$, df: $4, p<0.0001)$. Moreover, Stat $5 b$-deficient cell lines grew out with a delay of $\sim 12$ weeks post infection, whereas Stat $5 a$-deficient cells required about 6 weeks to form a stable cell line similar to wt lines, which succeeded to $100 \%$ to grow into stable cell lines (12/12). The absence of Stat5a and $S t a t 5 b$ required an enhanced BCR/ABL expression level (indicated by higher mean fluorescence intensity in the FACS analysis), which was also evident in western blot analysis (Supplementary Figure 2a and b). In line, the $\mathrm{IC}_{50}$ level for the BCR/ABL-inhibitor, imatinib were enhanced in Stat5b-deficient cells (Supplementary Figure 2b). When analyzing cell cycle progression of established cell lines by 
a

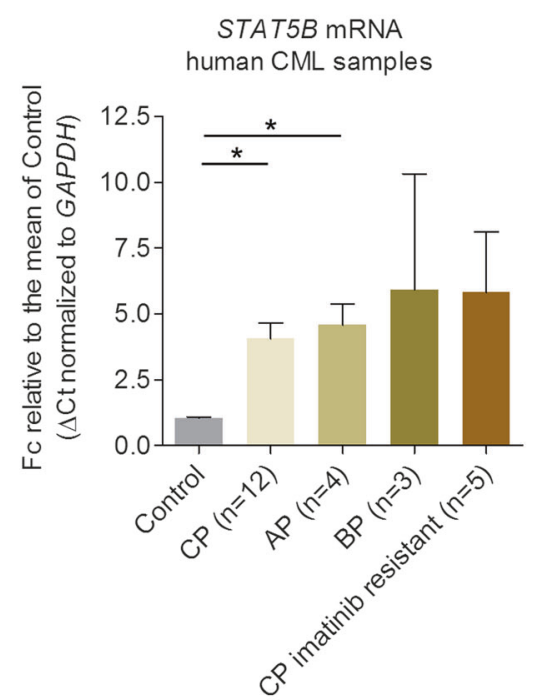

scrambled shRNA

Stat5a shRNA

Stat5b shRNA

b
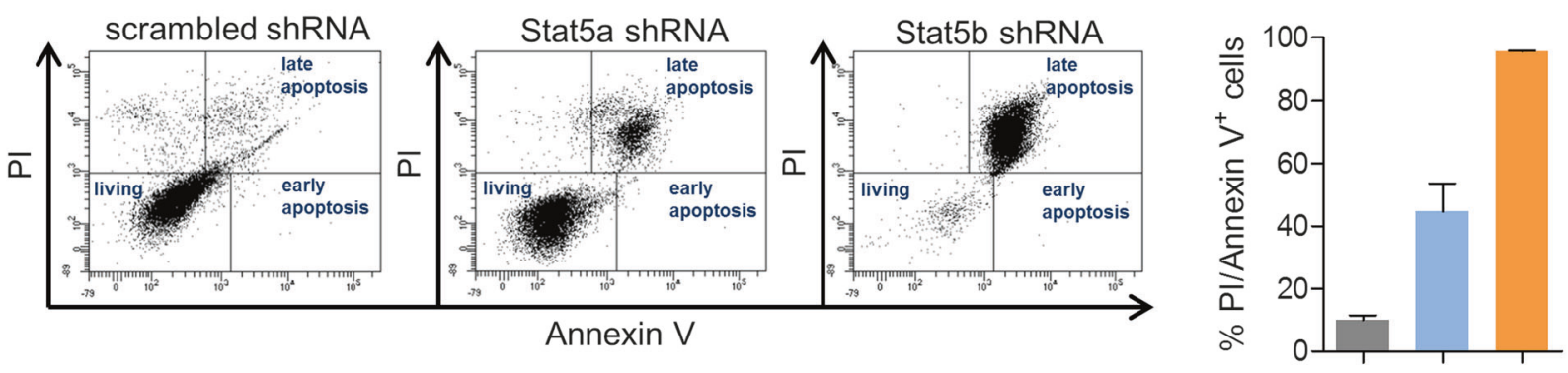

C

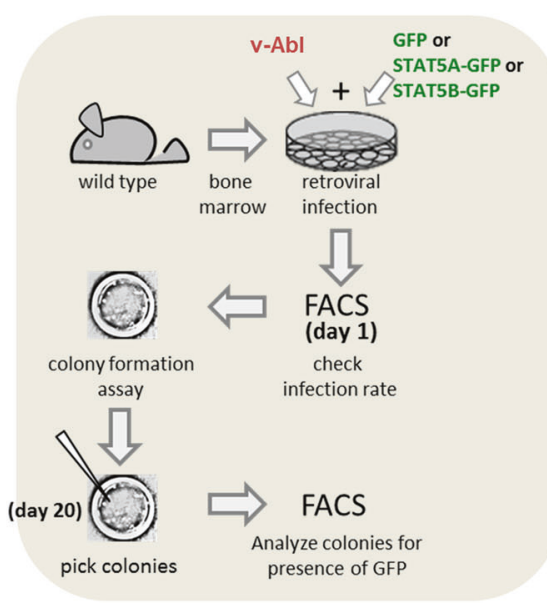

FACS, we observed consistently reduced numbers of cells in the $\mathrm{S}$ phase in Stat $5 b^{-/-}$cells (Fig. 2c, left panel). Growth curves over a period of 10 days confirmed the reduced cell proliferation upon STAT5B deficiency (Fig. 2c, right panel). These data indicate a role for STAT5B during the initial transformation process and for cell proliferation driven by $\mathrm{BCR} / \mathrm{ABL}$.

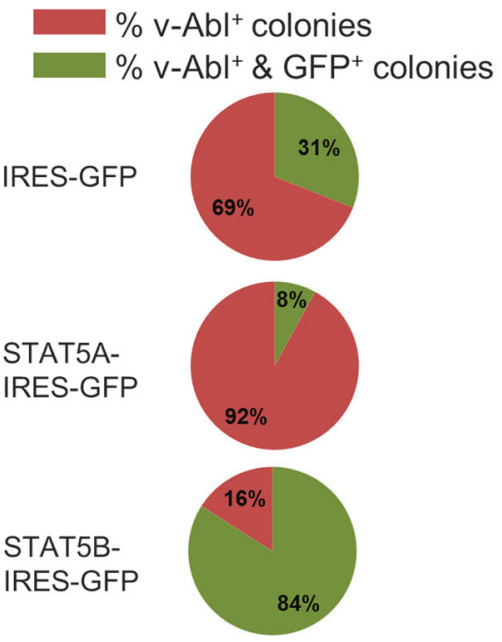

STAT5B is required for leukemogenesis and tumor formation in vivo

Deletion of $S t a t 5 a / b$ impairs leukemic cell growth in vivo [8, 9, 33, 34]. To dissect the individual contribution of STAT5A and STAT5B to lymphoid tumor formation, we injected $S t a t 5 a^{-/-}$, Stat $5 b^{-/-}$, or wt $\mathrm{BCR} / \mathrm{ABL}^{\mathrm{p} 185+}$ cell 
Fig. 1 STAT5B controls transformation and survival of BCR/ABL ${ }^{+}$ cells. a qPCR for $S T A T 5 B$ in human CML samples. Fold change of $S T A T 5 B$ mRNA levels compared to the mean level of control bone marrow (BM) samples. Control BM was derived from healthy individuals $(n=3)$; untreated CML patients in chronic phase (CP) $(n=12)$, acute phase (AP) $(n=4)$ or blast phase (BP) $(n=3)$ and relapsed imatinib-resistant patients in CP $(n=5)$. Error bars represent mean \pm SEM. Results were normalized to GAPDH mRNA expression. Levels of significance were calculated using Kruskal--Wallis test followed by Dunn's test. b Representative FACS plots (Annexin-V/PI stainings) of BCR/ABL ${ }^{\text {185+ }}$ cells with shRNA-mediated knockdown of Stat5a or Stat $5 \mathrm{~b}$. Scrambled shRNA was used as control. Right: Percentages of Annexin-V/PI-double positive BCR/ABL ${ }^{185+}$ cell lines with shRNAmediated knockdown of Stat5a or Stat5b ( $n=2$ cell lines/construct). Error bars represent mean \pm SEM. Levels of significance were calculated using Kruskal-Wallis test followed by Dunn's test. c Co-infection of BM cells with $\mathrm{Ab}-\mathrm{MuLV}$ (encoding v-Abl) and vectors expressing STAT5A or STAT5B (infection rates are provided in Supplementary Figure 1c) were plated in growth factor-free methylcellulose $(n=2$ cell lines/construct). Mean percentages of colonies carrying STAT5A and STAT5B are indicated in pie charts. STAT signal transducers and activators of transcription, BM bone marrow, wt wild type, qPCR quantitative PCR, CML chronic myeloid leukemia, mRNA messenger RNA, PI propidium iodide, shRNA short hairpin RNA

a
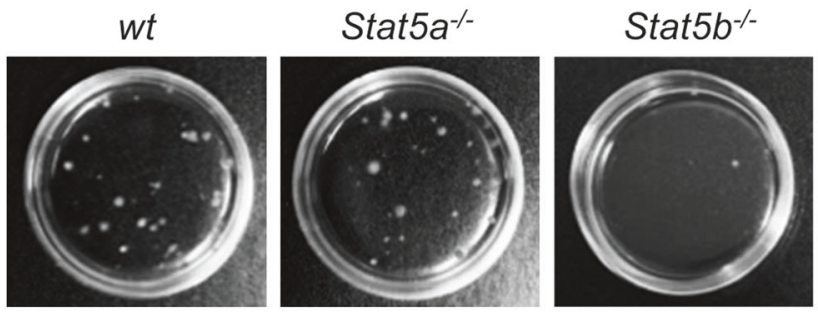

b

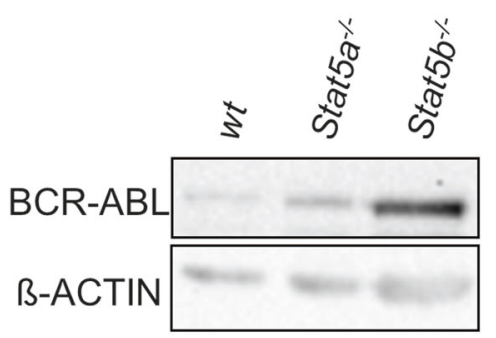

C lines subcutaneously into NSG mice. Stat $5 b^{-/-}$cells elicited significantly smaller tumors than $\operatorname{Stat} 5 a^{-/-}$or wt cell lines (Fig. 3a). To model a systemic disease, we injected the cell lines intravenously into NSG mice. We observed a significantly prolonged survival of mice that had received Stat $5 b^{-/-}$cells compared to the cohorts that were transplanted with $S t a t 5 a^{-/-}$or wt cell lines (Fig. 3b, left panel). The later time point of disease onset in $S t a t 5 b^{-/-}$transplanted mice was paralleled by reduced numbers of leukemic $\left(\mathrm{CD}^{+} 9^{+}\right)$cells in the BM (Supplementary Figure 3a). Frequencies of leukemic cells in the blood and spleen as well as white blood cell counts (WBCs) were comparable to those of the other cohorts (Supplementary Figure 3a and b). To gain more insight into the kinetics of disease development, we repeated the experiment and followed expansion of $\mathrm{GFP}^{+}$cells over time (Fig. 3b, right panel and Supplementary Figure 3c). Whereas leukemic cells were hardly present on day 5 in all experimental groups, a clear reduction of $\mathrm{GFP}^{+}$leukemic cells was evident on day 8 in the

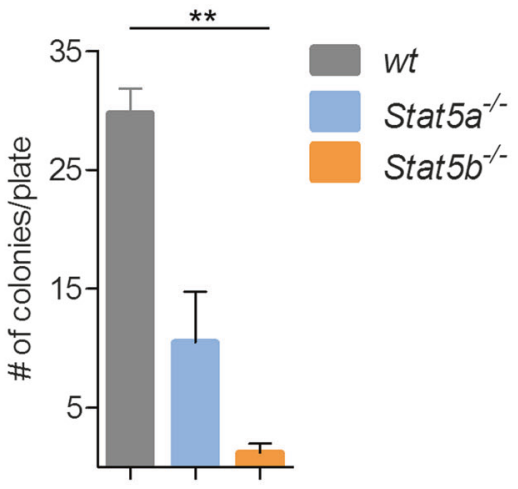

cell cycle analysis

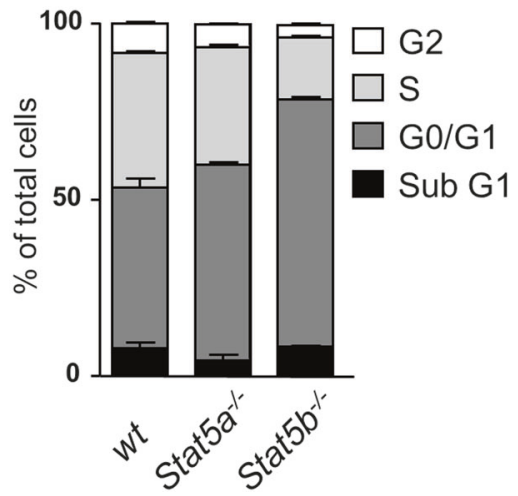

growth curve

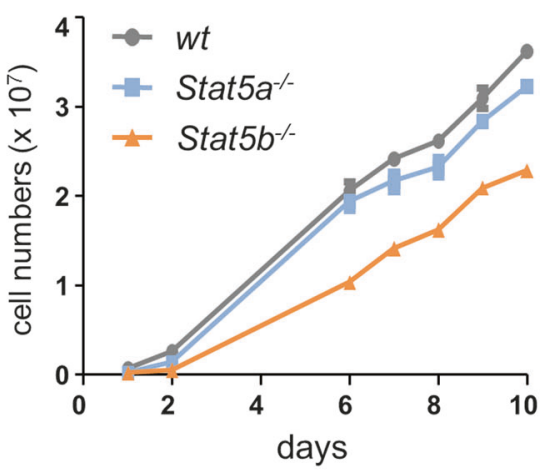

Fig. 2 STAT5B controls initial transformation and cell proliferation. a BM cells of wt, Stat $5 a^{-/-}$, or Stat $5 b^{-/-}$mice were infected with a retrovirus encoding $\mathrm{BCR} / \mathrm{ABL}^{\mathrm{p} 185}$ and plated in growth factor-free methylcellulose. Representative pictures of colony formation assays (CFA) are depicted. Bar graph summarizes data obtained from 4 cell lines/genotype each in technical duplicates. Error bars represent mean \pm SEM. Levels of significance were calculated using Kruskal-Wallis test followed by Dunn's test. b Protein levels of BCR/ABL in wt, Stat $5 a^{-/-}$, or Stat $5 b^{-/-}$cell lines as determined by immunoblotting.
One representative blot is shown. $\beta$-Actin served as a loading control. c Cell cycle profiles analyzed by PI-staining of BCR/ABL ${ }^{\text {p185 }}$-transduced cell lines $(n=2$ cell lines/genotype). Error bars represent mean \pm SEM. Right: Growth curves of established wt, Stat $5 a^{-/-}$, or Stat $5 b^{-/-}$BCR/ABL ${ }^{\text {p185+ }}$ cell lines $(n=2$ cell lines/genotype). Error bars represent mean \pm SEM. Levels of significance were calculated using Kruskal-Wallis test followed by Dunn's test. STAT signal transducers and activators of transcription, BM bone marrow, wt wild type, PI propidium iodide 
a s.c. injection of BCR-ABL-p185 ${ }^{+}$cell lines

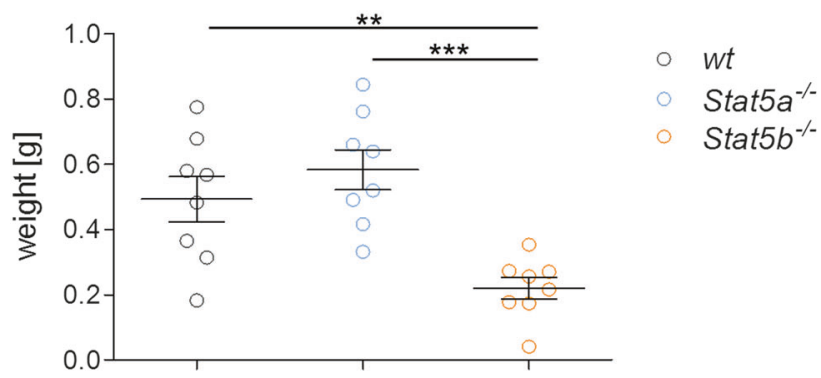

b

i.v. injection of BCR-ABL-p185 ${ }^{+}$cell lines

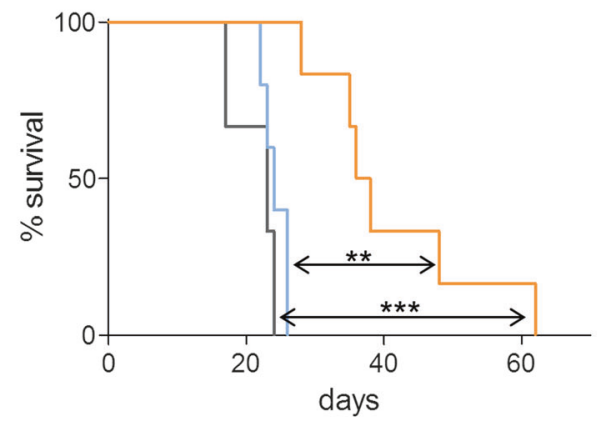

- wt
- Stat5a $a^{-/}$
$-S_{\text {Stat } 5 b^{-1}}$

C

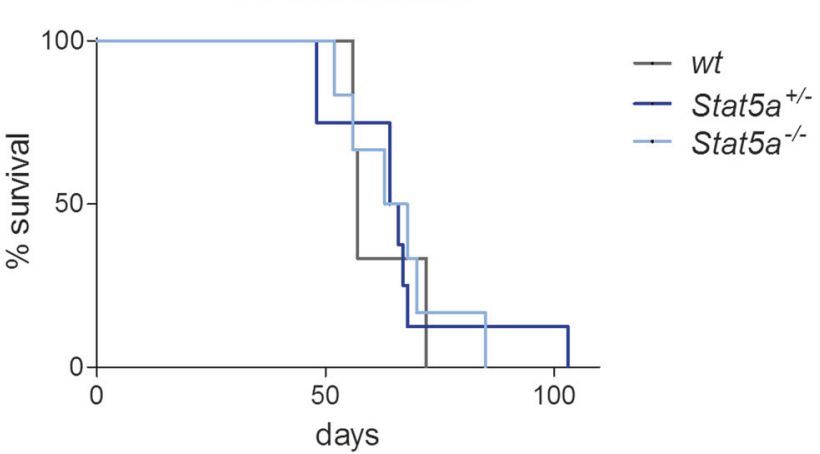

Fig. $3 \mathrm{BCR} / \mathrm{ABL}$-induced tumor formation in vivo is impaired upon loss of STAT5B. a Left: Subcutaneous injection of BCR/ABL ${ }^{185+}$ established cell lines into NSG mice ( $n=8$ per genotype). Bar graph summarizes tumor weights. Levels of significance were calculated using one-way ANOVA. Error bars represent mean \pm SEM. Right: Representative pictures of tumor sizes are depicted. b Kaplan-Meier plot of NSG mice that have received an intravenous injection (i.v.) of wt, Stat $5 a^{-1-}$, or Stat $5 b^{-/-}$BCR/ABL ${ }^{\mathrm{p} 185+}$ cells ( $n \geq 6$ per genotype). Log-rank (Mantel-Cox) test was used to calculate levels of significance. Right: I.v. injection of wt, Stat $5 a^{-/-}$, or Stat $5 b^{-/-}$BCR/ $\mathrm{ABL}^{\mathrm{p} 185+}$ cells into NSG mice. Three mice per genotype were sacrificed on day 5 , day 8 , and day 11 upon injection of $\mathrm{BCR} / \mathrm{ABL}^{\mathrm{p} 185+}$

BM, spleen, and in the peripheral blood in mice that had received Stat $5 b^{-1-}$ cells. In BM and blood, this difference extended to day 11.

To mimic disease development in people, we injected a retrovirus encoding $v$-abl intraperitoneally into new-born mice inducing a slowly evolving mono- or oligo-clonal

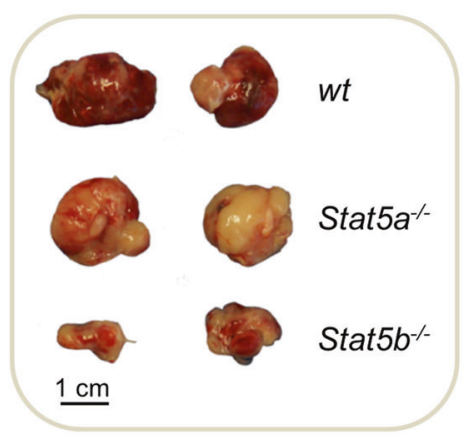

bone marrow

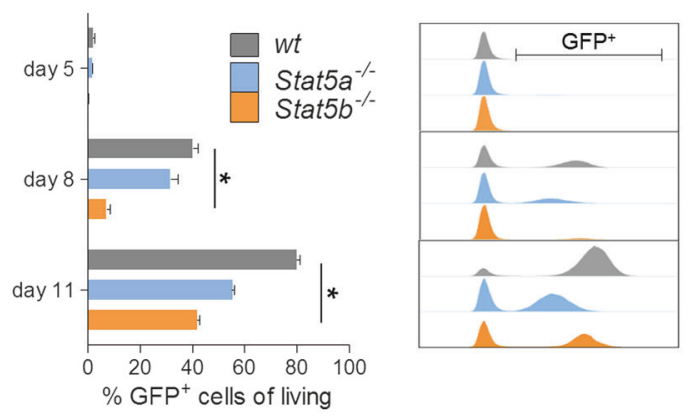

new born infection

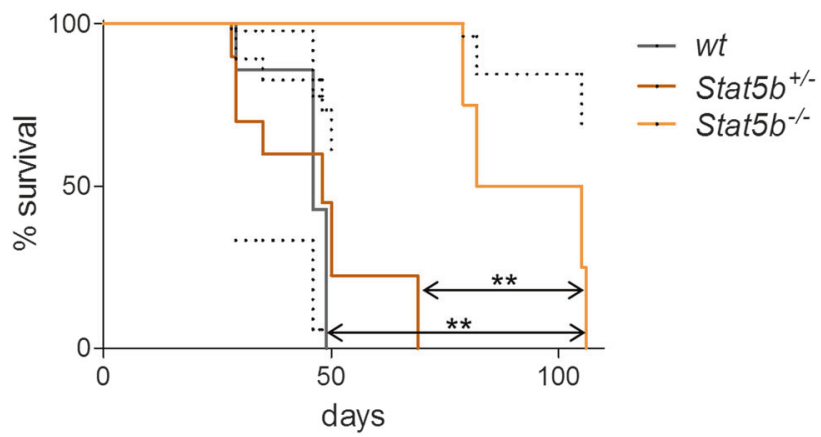

cells. Quantitative analysis via FACS for $\mathrm{GFP}^{+} \mathrm{BCR} \mathrm{ABL}^{\mathrm{p} 185+}$ cells in the $\mathrm{BM}$ ( $n=3$ per genotype and day) as well as representative histograms of each day and phenotype are provided. Error bars represent mean \pm SEM. Levels of significance were calculated using Kruskal-Wallis test followed by Dunn's test. c Survival plots after new-born infections using Ab-MulV (encoding v-abl) comparing left: wt, Stat $5 a^{+-}$, and Stat5 $a^{-/-}$mice ( $n \geq 3$ per genotype) or right: wt, $S t a t 5 b^{+/-}$, and $S t a t 5 b^{-/-}$mice ( $n \geq 4$ per genotype). Log-rank (Mantel-Cox) test was used to calculate levels of significance. NSG NOD.Cg-Prkdc $c^{\text {scid }} I l 2 \mathrm{rgtm}^{I W j l} / \mathrm{SzJ}$, ANOVA analysis of variance, IFN interferon, STAT signal transducers and activators of transcription, wt wild type, GFP green fluorescent protein

disease. Stat $5 a^{-/-}$and Stat $5 b^{-/-}$mice and their heterozygous and wt littermates were injected 24 to $36 \mathrm{~h}$ after birth. Stat $5 a^{-/-}$, Stat $5 a^{+/-}$, and wt mice showed overlapping kinetics in the incidence of terminal disease. In contrast, Stat5b-deficient mice diseased significantly later than their Stat5b $b^{+/-}$and wt littermates (Fig. 3c). These data 
a

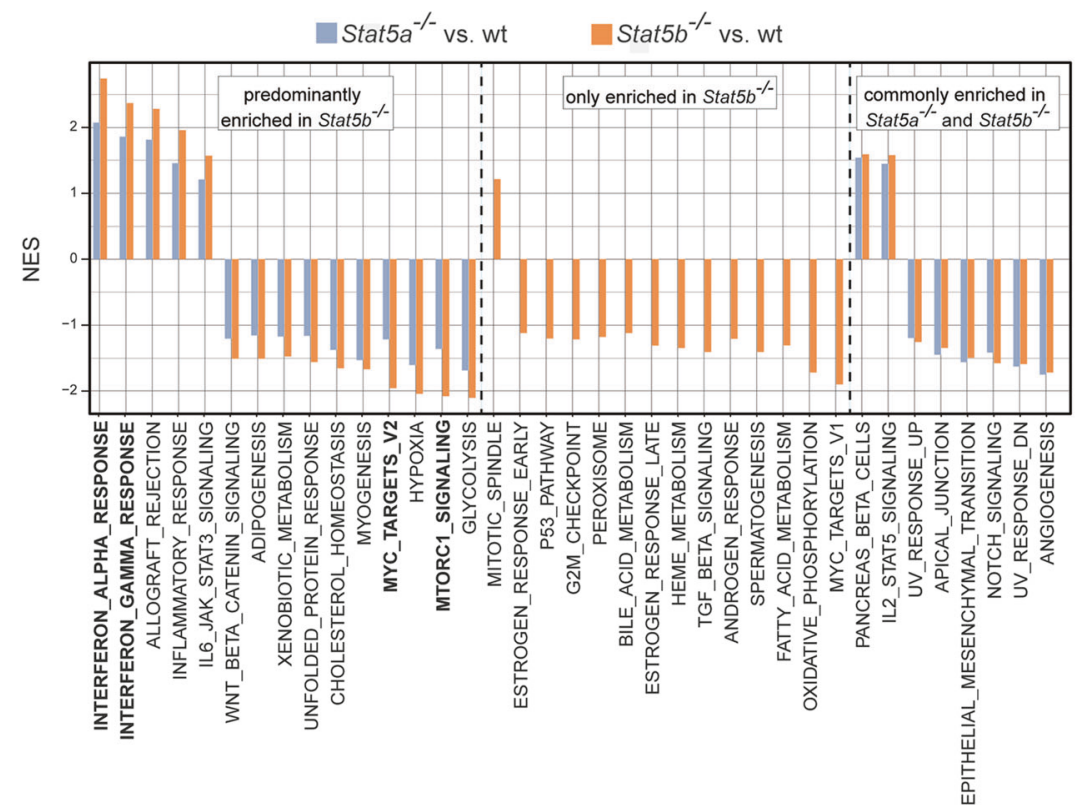

b

Stat5b/- vs. wt

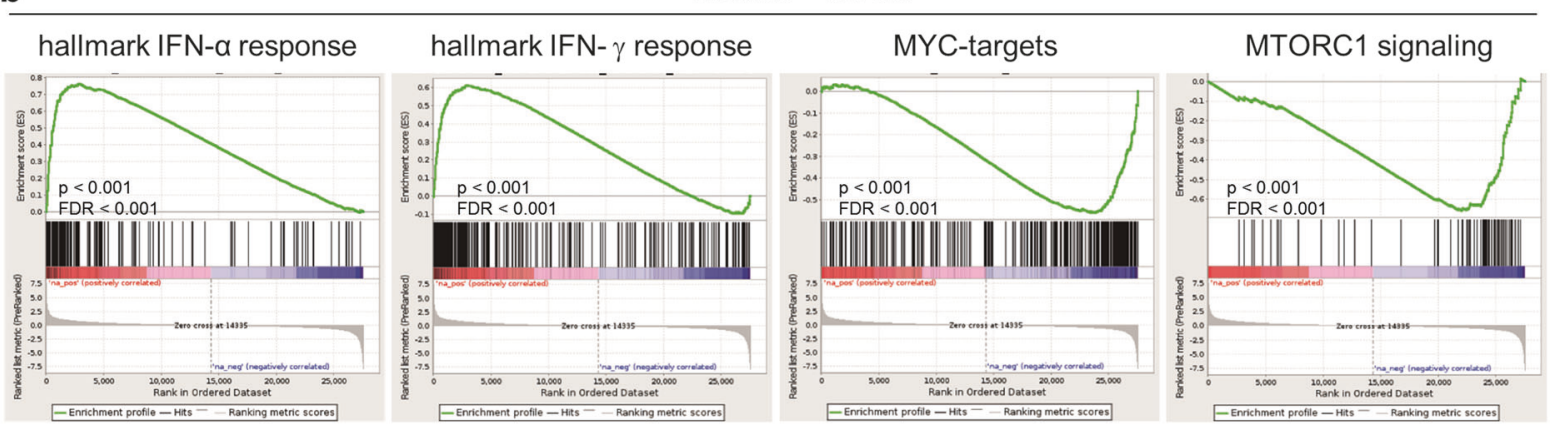

C

hallmark IFN- $\alpha$ response genes

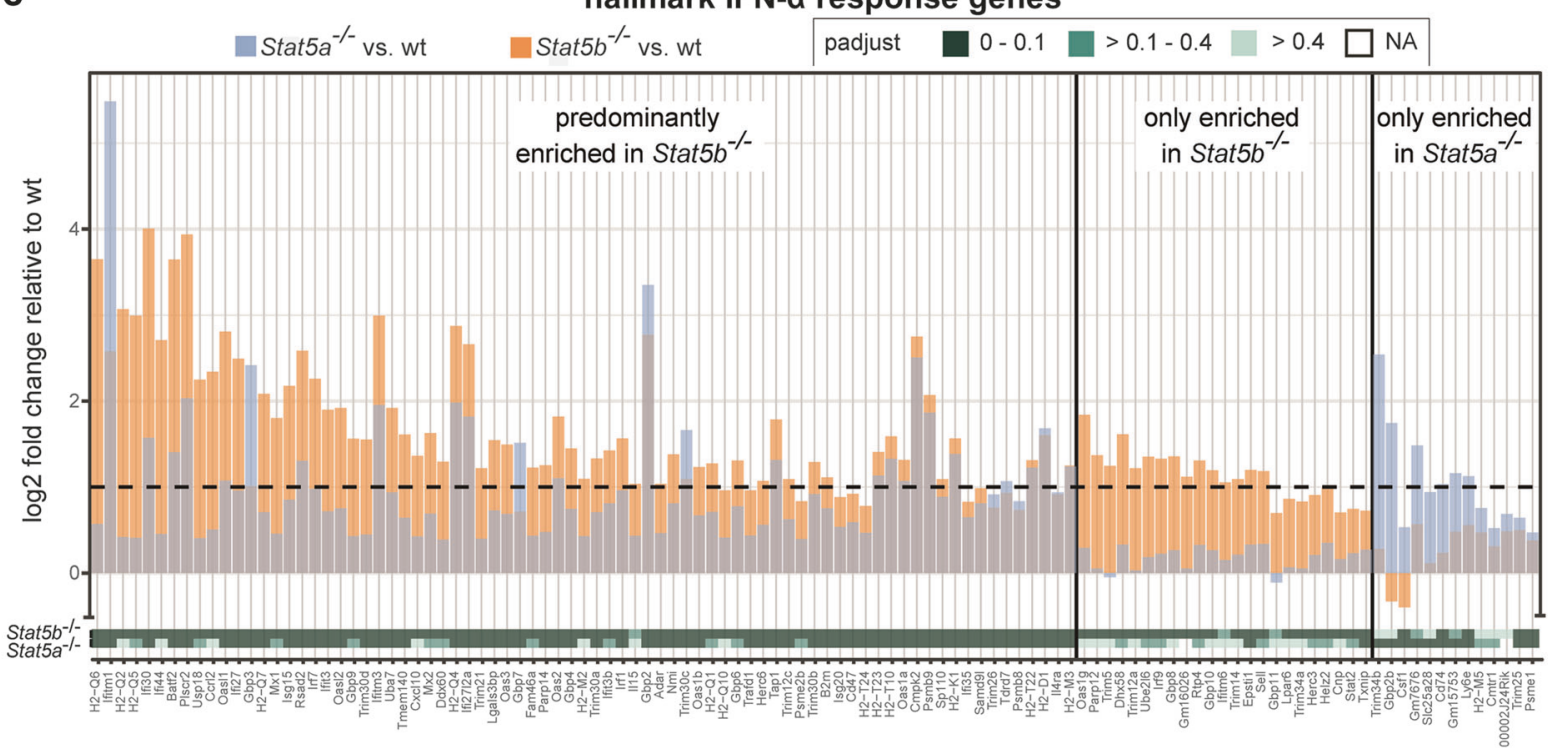




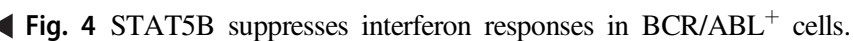
RNA-seq analysis was performed on $\mathrm{BCR} / \mathrm{ABL}^{\mathrm{p} 185+}$ cell lines derived from wt, Stat $5 a^{-1-}$ and Stat $5 b^{-/-}$mice. a Significantly (NES $>1$, FDR $<0.25$ ) enriched hallmark gene sets obtained from GSEA of $\log 2$ fold-change ranked gene lists from differential expression analysis of Stat $5 b^{-1-}$ (vs. wt) and Stat $5 a^{-1-}$ (vs. wt) BCR/ABL ${ }^{\text {p185+ }}$ cell lines. Gene sets more enriched in Stat $5 b^{-1-}$ (left panel), only enriched in Stat $5 b^{-1-}$ (middle panel), and equally enriched in Stat5 $b^{-1-}$ and Stat $5 a^{-1-}$ (right panel) are shown. b Enrichment plots of the hallmark IFN- $\alpha$ response gene set from GSEA above and additional GSEA of

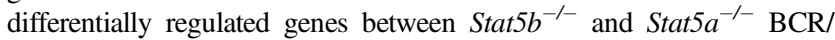
$\mathrm{ABL}^{\mathrm{p} 185+}$ cell lines. $\mathrm{c}$ The change in expression levels of genes that contribute to core enrichment of the hallmark IFN- $\alpha$ response gene set in Stat $5 b^{-/-}$(orange) and Stat $5 a^{-/-}$(blue) BCR/ABL ${ }^{185+}$ cell lines relative to wt $\mathrm{BCR} / \mathrm{ABL}^{\mathrm{p} 185+}$ cell lines and the significance of this change ( $p$-adjust, see legend) is shown. IFN interferon, STAT signal transducers and activators of transcription, wt wild type, NES normalized enrichment score, GSEA gene set enrichment analysis, $p$-adjust Benjamin-Hochbert corrected $p$ value, FDR false discovery rate

verify the privileged role for STAT5B in BCR/ABLinduced leukemia in vivo.

\section{STAT5B suppresses IFN responses in BCR/ABL ${ }^{+}$cells}

To gain insights into how STAT5B interferes with BCR/ ABL-induced leukemogenesis, we performed RNA-seq analysis. 881 genes were upregulated and 608 genes were downregulated exclusively in Stat $5 b^{-/-}$cells, compared to wt cells (Supplementary Figure 4, Supplementary Tables 1 and 2).

GSEA revealed three distinct groups: we found pathways that are (i) significantly higher enriched in Stat $5 b^{-/-}$than in Stat $5 a^{-/-}$cells, (ii) those which are exclusively enriched in Stat $5 b^{-/-}$cells and (iii) those which are commonly regulated in both genotypes (Fig. 4a). IFN signaling comprised a major deregulated pathway; IFN- $\alpha$ and IFN- $\gamma$ responses were upregulated in Stat5a $a^{-/-}$and Stat5b $b^{-/-}$cells, the extent being significantly higher in Stat $5 b^{-/}$cells (Fig. 4a and Supplementary Figure 5). Downregulated pathways contained MYC-, MTORC1 signaling, and glycolysis-in line with the proposed role of STAT5 in tumor formation (Fig. 4a). Enrichment plots underline the increased prevalence of hallmark IFN- $\alpha$ and IFN- $\gamma$ genes and the decreased abundance of MYC targets and MTORC1 signaling in Stat $5 b^{-1-}$ (Fig. 4b) and of MTORC1 targets in Stat5a ${ }^{-/}$cells (Supplementary Figure 6a and $b$ ).

Genes that contribute to the core enrichment of hallmark IFN- $\alpha$ and IFN- $\gamma$ response were subdivided into those which are predominantly enriched in Stat $5 b^{-1-}$, those which are only enriched in $\mathrm{Stat}_{5 b^{-/}}$, and those which are only enriched in $\mathrm{Stat}_{5 a^{-/-}}$cells. Key IFN- $\alpha-$ and IFN- $\gamma$ responsive genes were found in the "only enriched in

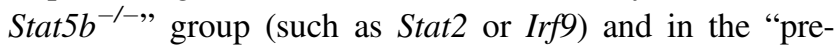

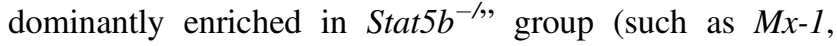
$M x$-2, or Irf7) (Fig. 4c and Supplementary Figure 7). The significantly higher impact on IFN-dependent gene regulation upon loss of STAT5B was verified by quantitative PCR (qPCR) for $I F N-\gamma$ and $I F N-\alpha$ as well as the IFN- $\alpha$ dependent immediate gene $M x-1$ (Fig. 5a). STAT1 and STAT2 are major transcriptional regulators downstream of IFN signaling. Cells lacking STAT5B display enhanced pSTAT1 and pSTAT2 levels compared to wt or Stat5a $a^{-/}$ cell lines (Fig. 5b). To test whether the effect extends to human $\mathrm{BCR} / \mathrm{ABL}^{+}$leukemia, we ablated STAT5A or STAT5B via shRNA-mediated knockdowns in K562 cells. Efficiencies of knockdowns were verified by immunoblotting (Supplementary Figure 8a). We monitored the outgrowth of shRNA-expressing cells in the presence of their non-transfected counterparts. Whereas loss of STAT5A led to a mild effect, the loss of STAT5B associated with a significant growth disadvantage (Fig. 5c, left panel and Supplementary Figure 8b). In line with the data obtained in the murine system, the expression levels of key interferon hallmark genes were markedly upregulated in STAT5Bdeficient K562 cells (Fig. 5c, right panel). Taken together, these data point at a suppressive role of STAT5B in IFN- $\alpha$ and IFN- $\gamma$ pathways upon transformation.

\section{Blocking of type I or type II IFN signaling enables Stat5 $b^{-/-}$cells to form colonies}

To investigate the functional consequences of the STAT5IFN axis, we next asked whether the elevated IFN signaling in Stat $5 b^{-1-}$ cells accounts for the reduced colony formation upon transformation by $\mathrm{BCR} / \mathrm{ABL}^{\mathrm{p} 185}$ or $\mathrm{BCR} / \mathrm{ABL}^{\mathrm{p} 210}$ oncogenes. To do so, we performed colony formation assays in the presence of IFNAR1 and/or IFN- $\gamma$ antibodies. Treatment with anti-IFNAR1 increased the number of colonies compared to IgG controls in Stat $5 b^{-/-}$cells (Fig. 6a). In line with the RNA-seq data, the effects were less pronounced in Stat $5 a^{-/-}$cells. Blocking of IFN- $\gamma$ elicited a comparable picture (Fig. 6b) as did the simultaneous blocking of type I and type II IFN signaling (Fig. 6c; $p=0.0208$ ). These data suggest that blockage of IFNAR1 signaling or IFN- $\gamma$ restores the transformation capacity of Stat $5 b^{-/-}$cells.

\section{IFN responses are downregulated in leukemic patients harboring STAT5B mutations}

Genome-wide screening of cancer patients is identifying increasing numbers of patients harboring somatic mutations in STAT5B (https://cancer.sanger.ac.uk/cosmic). These mutations are supposed to drive disease [21-24]. We hypothesized that leukemic cells derived from these patients show downregulation of IFN responses.

To test this, we performed RNA-seq of human STAT5B mutant T-LGLL samples using STAT5B-wt T-LGLL samples as controls. We identified 256 significantly 
a

IFN- $\gamma$ mRNA

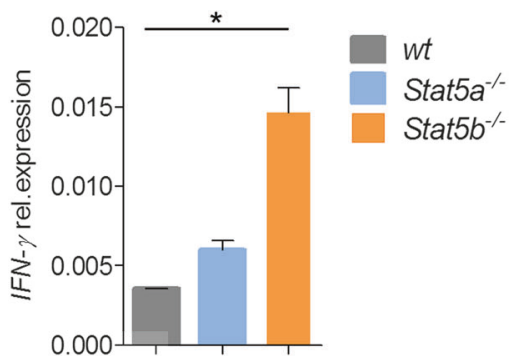

IFN- $\alpha$ mRNA

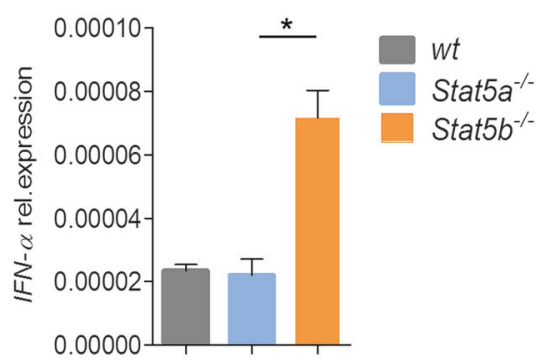

Mx-1 mRNA

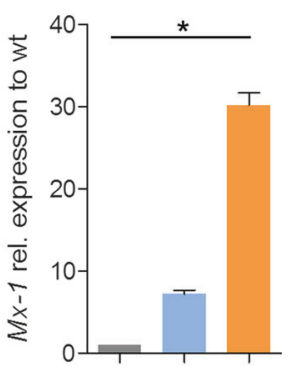

wt

Stat5a $a^{-/-}$

Stat $5 b^{-/-}$

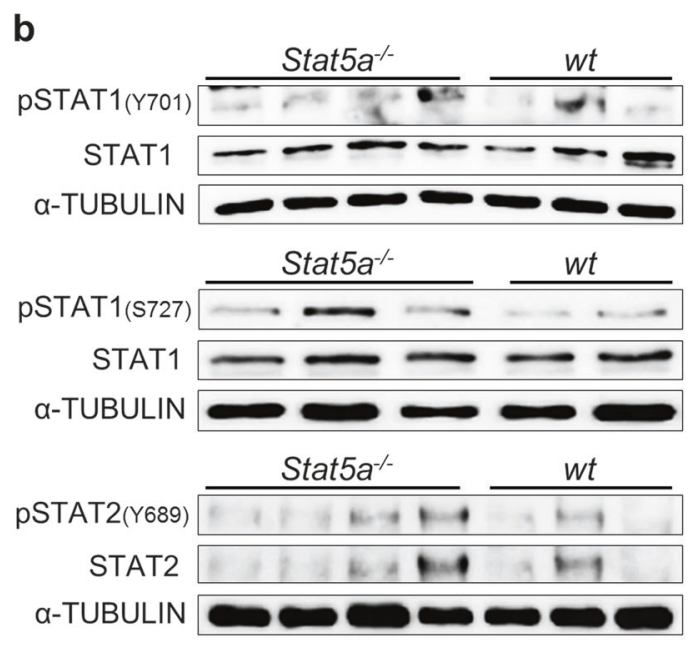

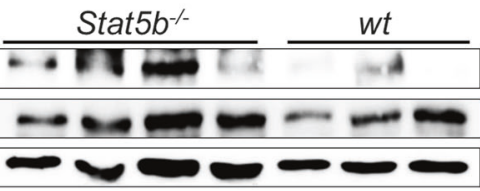

Stat $5 b^{-/-}$

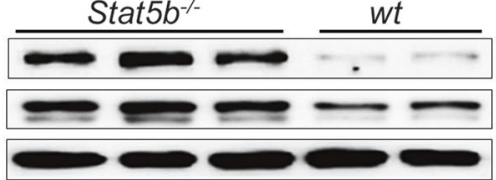

Stat $5 b^{-/ 2}$

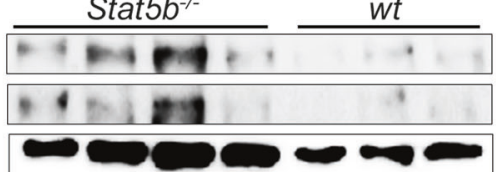

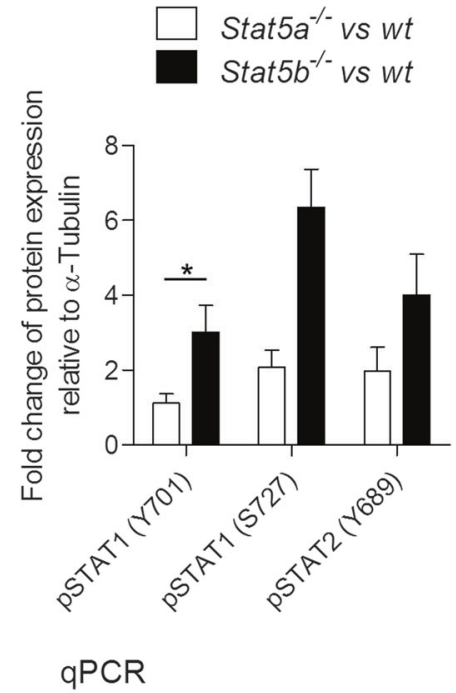

(IFN responsive genes)

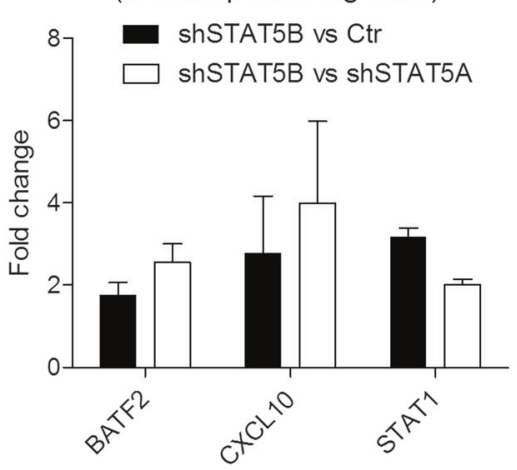

Fig. $5 \mathrm{IFN}-\alpha$ and $\mathrm{IFN}-\gamma$ responses are impaired in $\mathrm{BCR} / \mathrm{ABL}^{\mathrm{p} 185+}$ Stat $5 b^{-/-}$cells. qPCRs of wt, Stat $5 a^{-/-}$, or Stat $5 b^{-/-} \mathrm{BCR}^{\mathrm{A}} \mathrm{ABL}^{\mathrm{p} 185+}$ cell lines for a $I F N-\gamma, I F N-\alpha$, and $M x-1$ mRNA expression $(n \geq 3$ cell lines/genotype). Error bars represent mean \pm SEM. Levels of significance were calculated using Kruskal-Wallis test followed by Dunn's test. b Protein levels of pSTAT1(pS727, pY701), pSTAT2(pY698), STAT1 and STAT2 in wt, Stat $5 a^{-/-}$, or Stat $5 b^{-/-}$BCR/ABL ${ }^{\text {p185+ }}$ cells as determined by immunoblotting (each lane represents an independent cell line). Right: Densitometric analysis of pSTAT1(pS727, pY701) and pSTAT2(pY698) protein levels normalized to total protein loaded and wt. Error bars represent mean \pm SEM. Levels of significance were calculated via Wilcoxon-Mann-Whitney test. c Outgrowth of K562 cells expressing shRNAs against STAT5A $(n=1)$, STAT5B $(n=3)$, and Control $(\mathrm{Ctr}=$ Renilla, $n=1)$, in the presence of their non-transfected counterparts. Percentages of shRNA-expressing cells were detected by GFP expression and analyzed by flow cytometry over a period of 2 months post infection. Right: K562 cells were treated with shSTAT5A, shSTAT5B, or Ctr shRNA and sorted for $\mathrm{GFP}^{+}$cells. Fold change of mRNA expression levels were detected via qPCR for BATF2, CXCL10, and STAT1. Error bars represent mean \pm SEM. Levels of significance were calculated via Wilcoxon-Mann-Whitney test. IFN interferon, qPCR quantitative PCR, BM bone marrow, STAT signal transducers and activators of transcription, wt wild type, shRNA short hairpin RNA, mRNA messenger RNA, GFP green fluorescent protein 
a $\quad 10 \mu \mathrm{g} / \mathrm{ml}$ IFNAR1 blocking $A B$ added

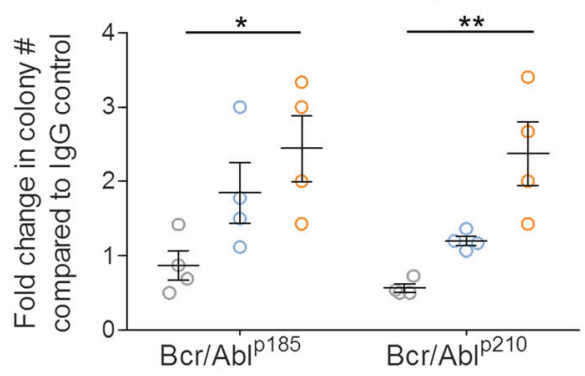

C $10 \mu \mathrm{g} / \mathrm{ml} \mathrm{IFN}-\gamma$ and IFNAR1 blocking AB added

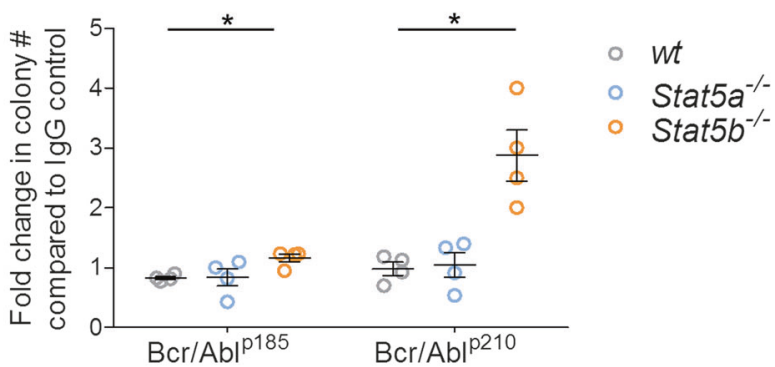

Fig. 6 Blockage of IFN- $\alpha$ or IFN- $\gamma$ signaling restores the capacity of Stat $5 b^{-1-}$ cells to form colonies. BM cells of wt, Stat $5 a^{-/-}$or Stat $5 b^{-1-}$ mice were infected with a retrovirus encoding BCR/ABL ${ }^{\mathrm{p} 185}$ or $\mathrm{BCR} / \mathrm{ABL}^{\mathrm{p} 210}$ and plated in growth factor-free methylcellulose. In addition $10 \mu \mathrm{g} / \mathrm{ml}$ antibodies (Ab) blocking a IFNAR1 or b IFN- $\gamma$ or $\mathbf{c}$ combination of both (in total $10 \mu \mathrm{g} / \mathrm{ml})$ were added $(n=4$ per

upregulated and 376 significantly downregulated genes (Fig. 7a and Supplementary Table 3; $p$-adjust $<0.05$ and fold change $>2$ ). GSEA of this DEA revealed mainly negatively enriched gene sets, including IFN- $\alpha$ and IFN- $\gamma$ responses (Fig. 7b, c). Only one gene set (HEME metabolism) was positively enriched (data not shown).

The opposite gene regulation pattern of human STAT5B mutant and murine Stat $_{5} b^{-/}$leukemias regarding IFN responses prompted us to compare the expression of a specific set of genes. We selected genes that were upregulated in the murine Stat $5 b^{-1-}$ samples and explored their expression in human STAT5B mutant leukemia. This approach identified nine IFN hallmark genes regulated in opposite directions: BATF2, HLA-DQB1, IFIT3, CXCL10, TNFAIP2, HLA-DQA1, HLA-DRB1, CDKNIA, and CD74 (Fig. 7d).

\section{Discussion}

Here, we investigated the role of STAT5 isoforms in BCR/ $\mathrm{ABL}^{+}$leukemia, a disease that ceases upon combined loss of STAT5A and STAT5B [9]. The use of Stat5a $a^{-1}$ - and Stat $5 b^{-/-}$-knockout mice allowed investigating individual contributions of STAT5B and STAT5A to the development of disease. b $\quad 10 \mu \mathrm{g} / \mathrm{ml} \mathrm{IFN}-\gamma$ blocking $\mathrm{AB}$ added
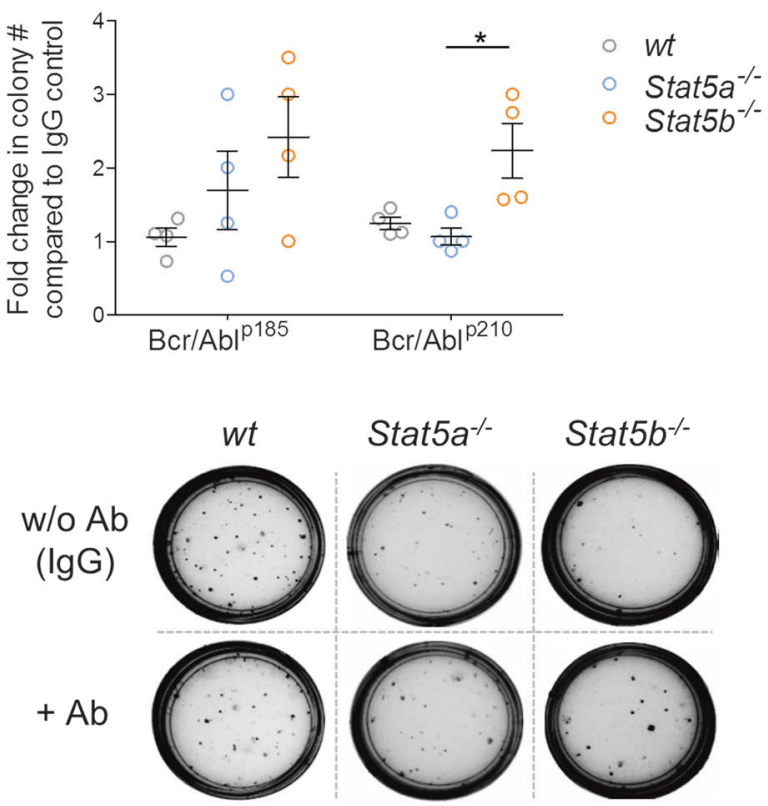

genotype). Levels of significance were calculated using KruskalWallis test followed by Dunn's test. Error bars represent means \pm SEM. Right: representative pictures of CFA. IFN interferon, BM bone marrow, STAT signal transducers and activators of transcription, wt wild type, GSEA geneset enrichment analysis, CFA colony formation assays

Our study defines STAT5B as the critical isoform for the transformation of $\mathrm{BCR} \mathrm{ABL}^{+}$cells. Several lines of evidence support this conclusion; the enforced expression of STAT5B in $\mathrm{BCR} / \mathrm{ABL}^{+}$cells enhances cell proliferation, while knockdown decreases colony formation in vitro. In murine models, the lack of STAT5B prolongs tumor formation in vivo.

The privileged role of STAT5B for BCR/ABL-induced leukemogenesis is documented in reduced colony formation in the absence of STAT5B. The absence of STAT5A exerts minor effects. Similarly, the establishment of immortalized cell lines is severely hindered in the absence of STAT5B and demands enhanced levels of the BCR/ABL oncoprotein, whereas the absence of STAT5A is of minor impact. Once established, Stat $5 b^{-/-}$cells maintain a reduced proliferative capacity and induce leukemia significantly later. Confirmation stems from experiments where we applied a leukemia model using retroviral infection in new-born mice: Stat $5 b^{-1-}$ mice succumbed significantly later to leukemia. In contrast, Stat $5 a^{-/-}$cells-while showing a reduced but still existent capacity to transform in vitro-showed superimposable kinetics of disease onset as wt cells in both in vivo models.

The model of new-born infection adds another layer of complexity as STAT5B is absent in the entire organism including immunological tumor surveillance. In 
a

qval $<0.05$ and $|\log 2 \mathrm{fc}|>1 \bullet$ not_significant $\bullet$ significant

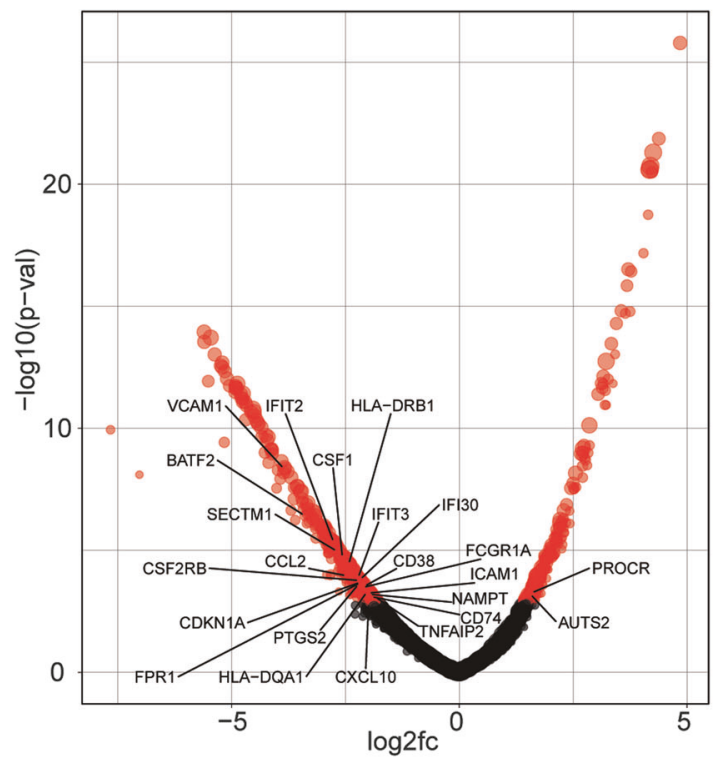

C

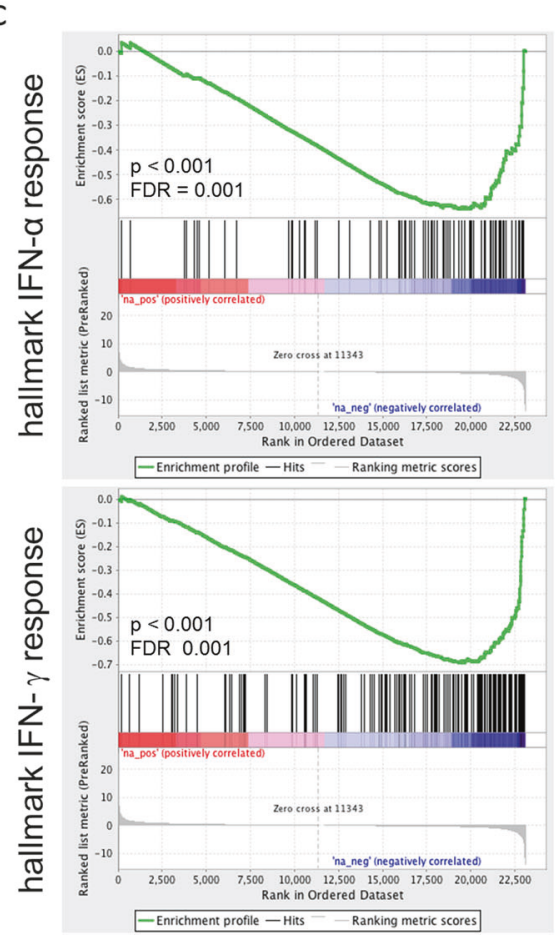

Fig. 7 IFN responses are enhanced in human STAT5B mutant T cell large granular lymphocyte leukemia (T-LGLL). a RNA-seq from STAT5B mutant $(n=4)$ and wt $(n=13)$ T-LGLL patient samples. Significantly differentially ( $q$ value $<0.05$ and fold change $>2$ ) upregulated $(n=256)$ or downregulated $(n=376)$ genes were identified. Deregulated genes belonging to IFN- $\alpha$ and IFN- $\gamma$ hallmark gene sets are indicated. Size of points corresponds to $\log C P M$ (counts per million) expression levels. b Significantly (NES $<-1.75$, FDR $<0.25$ ) negatively enriched hallmark gene sets obtained from GSEA of $\log 2$

d b
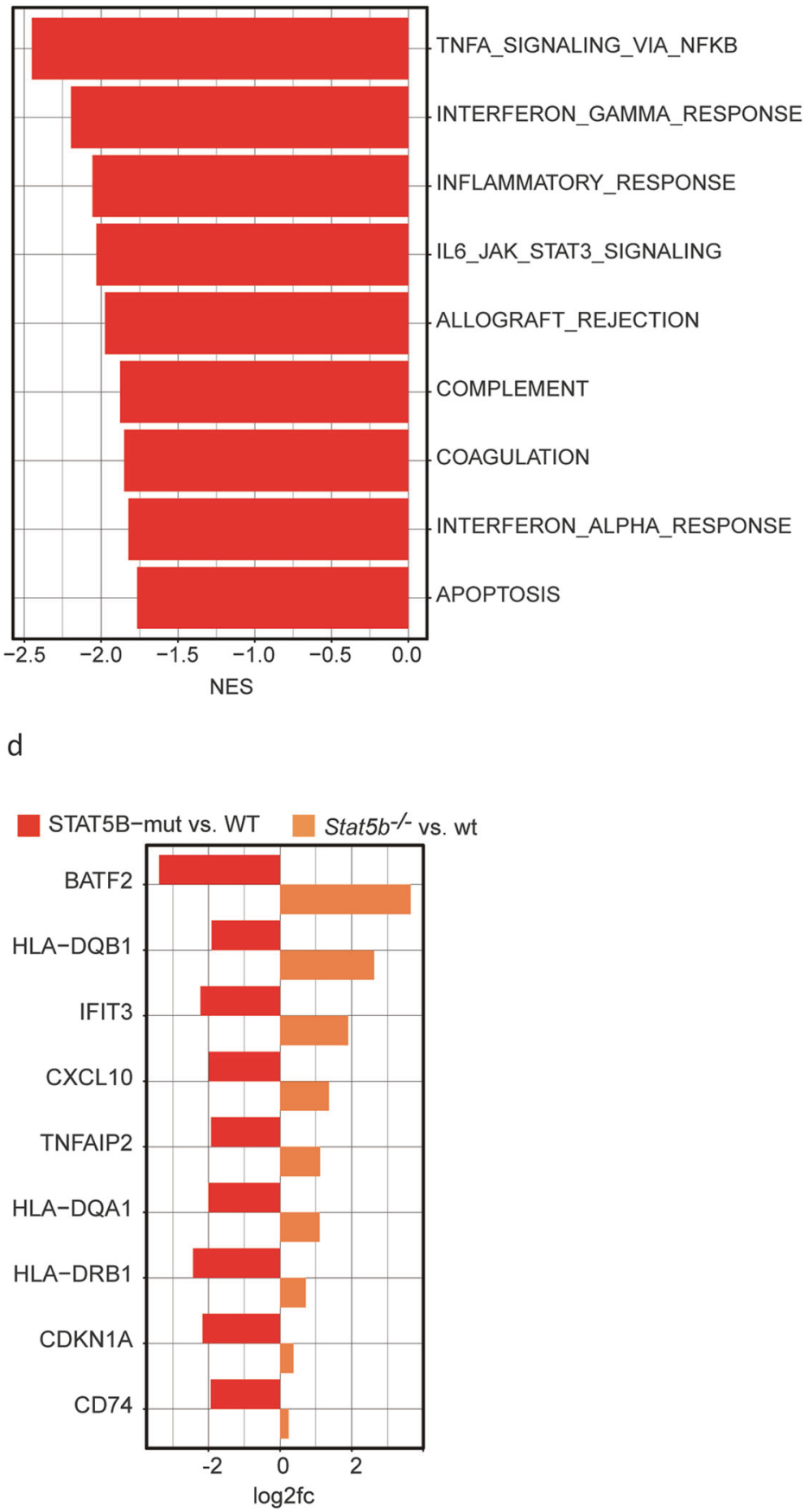

fold-change ranked gene lists from differential expression analysis of STAT5B mutant (vs. wt) T-LGLL cases. c Enrichment plots of the IFN- $\alpha$ and IFN- $\gamma$ hallmark gene sets from GSEA. d Genes significantly ( $p$-adjust $<0.05$ ) upregulated in $S_{a t} 5 b^{-/}$BCR/ABL $^{\mathrm{p} 185}$ cell lines and significantly ( $p$-adjust $<0.05)$ downregulated in STAT5B mutant T-LGLL cases. IFN interferon, STATB signal transducers and activators of transcription 5B, RNA-seq RNA-sequencing, wt wild type, GSEA geneset enrichment analysis, NES normalized enrichment score, FDR false discovery rate 
BCR/ABL-induced leukemia NK cells represent the primarily responsive cellular compartment which survey the tumor cells $[31,35,36]$. The fact that leukemia

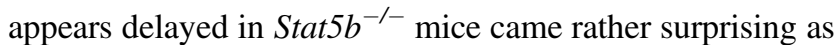
Stat $5 b^{-/-}$NK cells are less functional-which would rather promote leukemia formation ([37, 38] and own observations). In contrast to our expectations that an impaired NK cell-mediated tumor surveillance accelerates leukemogenesis, STAT5B-deficient animals disease significantly later. This indicates a pronounced defect of Stat $5 b^{-1-}$ mice in tumorigenesis, which cannot be outweighed by a decreased NK cell-mediated tumor surveillance. It also indicates that any therapeutic strategy blocking STAT5B will maintain beneficial effects despite inhibiting NK cell functions.

STAT5B is critical at two distinct steps of transformation; during the initial switch from a normal to a transformed cell as well as during the establishment and progression of leukemia in vivo. The role of STAT5B in the initial phase of transformation is reflected by the reduced capability to form colonies. Blocking of IFN signaling restored the capability of Stat $5 b^{-1-}$ BM cells to transform and form colonies. The transcriptional programs driven by IFN- $\alpha$ and IFN- $\gamma$ are significantly increased in $S t a t 5 b^{-/-}$ cells and only to a lesser extent in Stat5a ${ }^{-/-} \mathrm{BCR} / \mathrm{ABL}^{+}$ cells. An involvement of STAT5 in IFN signaling in other cellular systems has already been suggested [39-42]. Our study now poses the IFN-STAT5 axis in the core of Blymphoid tumorigenesis.

Despite undetectable IFN levels via enzyme-linked immunosorbent assay (data not shown), we observed a clear-cut phenotype upon blocking signaling via interfering antibodies. Treatments with anti-IFNAR1 or anti-IFN- $\gamma$ restored the ability of Stat $5 b^{-/-}$BM cells to transformpointing at the involvement of tonic IFN signaling. Tonic IFN signaling is characterized by a constant but low-level production of IFNs [43, 44]. Besides, during the initial transformation, cells encounter oncogenic stress and need to overcome the p53 response. In the latter, STAT5 was already predicted to have a critical role [45-47].

Even upon overcoming this initial hurdle and when the leukemic cell lines are established, STAT5B-deficient cells still display a significant disadvantage as fatal disease occurs with a delay in vivo. Here, the established role of STAT5B as cell cycle regulator comes into play; STAT5B controls cell cycle progression and its loss interferes with proliferation and motility of tumor cells [20, 27, 48-50]. We currently do not know how significant the STAT5Bmediated suppressive effect on IFN signaling is during this advanced stage of transformation. The fact that IFNs have been used as therapeutics for decades to treat patients suffering from $\mathrm{BCR} / \mathrm{ABL}^{+}$leukemia suggests a key role for IFN in this disease [44, 51-53]. Any therapeutic strategy that interferes with STAT5B signaling might also enhance
IFN production of the leukemic cells that may support a curative effect.

Our data may be of direct clinical relevance: current studies propose STAT5B as a key driver in human hematological tumors [20-24]. In that sense, the activation of STAT5B might be an asset during transformation and explain why gain-of-function mutations are found in hematological disorders at increased frequency. Our analysis of patient-derived samples with STATSB mutations confirms this concept and extends it to the human hematopoietic system. Patients suffering from lymphoid malignancies with an activating STAT5B mutation display deregulated IFN signaling pathways. We found many genes being mirror-inverted when compared to the murine Stat $5 b$ deficient leukemic cells.

Our results contribute to the knowledge of how STAT5B controls tumorigenesis in the hematopoietic lineage, a finding that was originally described in STAT5B gain-offunction mouse models [15-17].

We provide a novel edge to the role STAT5B in transformation, besides controlling cell cycle, apoptosis, and p53 responses. STAT5B is required to suppress IFN signaling, which is necessary for cells to fully transform. A better understanding of the complex role of STAT5B in leukemia will enable the development of precision medicine strategies to treat disease.

\section{Availability of data and materials}

Due to constraints in the ethical permit, the raw sequencing data of patients is only available from the corresponding author upon reasonable request.

Acknowledgements We thank Peter Valent for providing patient CML samples; David Levy and Richard Moriggl for discussions and scientific input. For technical support, we thank Sabine Fajmann, Philipp Jodl, Rugaia Idris, Petra Kudweis, and Meryem Sen. Special thanks to Michaela Prchal-Murphy and the mouse facility team.

Funding This work was supported by the Austrian Science Fund (FWF-SFB 4706, 6101, 6103, 6106, 6107 to VS, TD, BS, and MM and 4701 and 4704 to PV; P24295-B23 to AH-K; J3578-B21 to WW), LH was supported by the IRP, NIDDK, and NIH. SM was supported by the European Research Council (M-IMM project), Academy of Finland, Finnish special governmental subsidy for health sciences, research and training, the Sigrid Juselius Foundation, and the Finnish Cancer Societies.

\section{Compliance with ethical standards}

Conflict of interest SM has received honoraria and research funding from Novartis, Pfizer, and Bristol-Myers Squibb (not related to this study). The other authors declare that they have no conflict of interest.

Publisher's note: Springer Nature remains neutral with regard to jurisdictional claims in published maps and institutional affiliations. 
Open Access This article is licensed under a Creative Commons Attribution 4.0 International License, which permits use, sharing, adaptation, distribution and reproduction in any medium or format, as long as you give appropriate credit to the original author(s) and the source, provide a link to the Creative Commons license, and indicate if changes were made. The images or other third party material in this article are included in the article's Creative Commons license, unless indicated otherwise in a credit line to the material. If material is not included in the article's Creative Commons license and your intended use is not permitted by statutory regulation or exceeds the permitted use, you will need to obtain permission directly from the copyright holder. To view a copy of this license, visit http://creativecommons. org/licenses/by/4.0/.

\section{References}

1. O'Shea JJ, Holland SM, Staudt LM. JAKs and STATs in immunity, immunodeficiency, and cancer. $\mathrm{N}$ Engl $\mathrm{J}$ Med. 2013;368:161-70.

2. Levine RL, Pardanani A, Tefferi A, Gilliland DG. Role of JAK2 in the pathogenesis and therapy of myeloproliferative disorders. Nat Rev Cancer. 2007;7:673-83.

3. Steelman LS, Pohnert SC, Shelton JG, Franklin, RA, Bertrand, FE, McCubrey, JA. JAK/STAT, Raf/MEK/ERK, PI3K/Akt and $\mathrm{BCR}-\mathrm{ABL}$ in cell cycle progression and leukemogenesis. Leukemia. 2004;18:189-218.

4. $\mathrm{Yu} \mathrm{H}$, Jove R. The STATs of cancer-new molecular targets come of age. Nat Rev Cancer. 2004;4:97-105.

5. Schwaller J, Parganas E, Wang D, Cain D, Aster, JC, Williams IR, et al. Stat5 is essential for the myelo- and lymphoproliferative disease induced by TEL/JAK2. Mol Cell. 2000;6:693-704.

6. Ilaria RL, Van Etten RA. P210 and P190(BCR/ABL) induce the tyrosine phosphorylation and DNA binding activity of multiple specific STAT family members. J Biol Chem. 1996;271:31704-10.

7. Spiekermann K, Pau M, Schwab R, Schmieja K,Franzrahe S, Hiddemann W. Constitutive activation of STAT3 and STAT5 is induced by leukemic fusion proteins with protein tyrosine kinase activity and is sufficient for transformation of hematopoietic precursor cells. Exp Hematol. 2002;30:262-71.

8. Hoelbl A, Kovacic B, Kerenyi MA, Simma, O, Warsch W, Cui Y, et al. Clarifying the role of Stat5 in lymphoid development and Abelson-induced transformation. Blood. 2006;107:4898-906.

9. Hoelbl A, Schuster C, Kovacic B, Zhu B, Wickre M, Hoelzl MA, et al. Stat5 is indispensable for the maintenance of bcr/abl-positive leukaemia. EMBO Mol Med. 2010;2:98-110.

10. Liu X, Robinson GW, Wagner KU, Garrett L, Wynshaw-Boris A, Hennighausen L. Stat5a is mandatory for adult mammary gland development and lactogenesis. Genes Dev. 1997;11:179-86.

11. Yamaji D, Na R, Feuermann Y, Pechhold S, Chen W, Robinson, $\mathrm{GW}$, et al. Development of mammary luminal progenitor cells is controlled by the transcription factor STAT5A. Genes Dev. 2009;23:2382-7.

12. Liu X, Robinson GW, Gouilleux F, Groner B, Hennighausen L. Cloning and expression of Stat5 and an additional homologue (Stat5b) involved in prolactin signal transduction in mouse mammary tissue. Proc Natl Acad Sci USA. 1995;92:8831-5.

13. Udy GB, Towers RP, Snell RG, Wilkins RJ, Park SH, Ram PA, et al. Requirement of STAT5b for sexual dimorphism of body growth rates and liver gene expression. Proc Natl Acad Sci USA. 1997;94:7239-44.

14. Moriggl R, Sexl V, Kenner L, Duntsch C, Stangl K, Gingras S, et al. Stat5 tetramer formation is associated with leukemogenesis. Cancer Cell. 2005;7:87-99.

15. Onishi M, Nosaka T, Misawa K, Mui AL, Gorman D, McMahon $\mathrm{M}$, et al. Identification and characterization of a constitutively active STAT5 mutant that promotes cell proliferation. Mol Cell Biol. 1998;18:3871-9.

16. Burchill MA, Goetz CA, Prlic M, O'Neil JJ, Harmon IR, Bensinger SJ, et al. Distinct effects of STAT5 activation on CD4+ and $\mathrm{CD} 8+\mathrm{T}$ cell homeostasis: development of CD4+CD25+ regulatory $\mathrm{T}$ cells versus $\mathrm{CD} 8+$ memory $\mathrm{T}$ cells. $\mathrm{J}$ Immunol. 2003;171:5853-64.

17. Kelly J, Spolski R, Imada K, Bollenbacher J, Lee S, Leonard WJ. A role for Stat5 in CD8 $+\mathrm{T}$ cell homeostasis. J Immunol. $2003 ; 170: 210-7$

18. Nieborowska-Skorska M, Slupianek A, Xue L, Zhang Q, Raghunath PN, Hoser G. et al. Role of signal transducer and activator of transcription 5 in nucleophosmin/ anaplastic lymphoma kinase-mediated malignant transformation of lymphoid cells. Cancer Res. 2001;61:6517-23.

19. Zhang Q, Wang HY, Liu X, Wasik MA. STAT5A is epigenetically silenced by the tyrosine kinase NPM1-ALK and acts as a tumor suppressor by reciprocally inhibiting NPM1-ALK expression. Nat Med. 2007;13:1341-8.

20. Rajala HLM, Eldfors S, Kuusanmaki H, van Adrichem AJ, Olson T, Lagstrom S. et al. Discovery of somatic STAT5b mutations in large granular lymphocytic leukemia. Blood. 2013;121:4541-50.

21. Kontro M, Kuusanmäki H, Eldfors S, Burmeister T, Andersson EI, Bruserud O. et al. Novel activating STAT5B mutations as putative drivers of T-cell acute lymphoblastic leukemia. Leukemia. 2014;28:1738-42.

22. Bandapalli OR, Schuessele S, Kunz JB, Rausch T, Stütz AM, Tal $\mathrm{N}$. et al. The activating STAT5B N642H mutation is a common abnormality in pediatric T-cell acute lymphoblastic leukemia and confers a higher risk of relapse. Haematologica. 2014;99:e188-92.

23. Kiel MJ, Velusamy T, Rolland D, Sahasrabuddhe AA, Chung F, Bailey $\mathrm{NG}$, et al. Integrated genomic sequencing reveals mutational landscape of T-cell prolymphocytic leukemia. Blood. 2014; 124:1460-72.

24. Nicolae A, Xi L, Pittaluga S, Abdullaev Z, Pack SD, Chen J, et al. Frequent STAT5B mutations in $\gamma \delta$ hepatosplenic T-cell lymphomas. Leukemia. 2014;28:2244-8.

25. Stark GR, Darnell JE. The JAK-STAT pathway at twenty. Immunity. 2012;36:503-14.

26. Ariyoshi K, Nosaka T, Yamada K, Onishi M, Oka Y, Miyajima A, et al. Constitutive activation of STAT5 by a point mutation in the SH2 domain. J Biol Chem. 2000;275:24407-13.

27. Pham HTT, Maurer B, Prchal-Murphy M, Grausenburger R, Grundschober E, Javaheri T, et al. STAT5BN642H is a driver mutation for T cell neoplasia. J Clin Invest. 2017;128:387-401.

28. Herrmann H, Sadovnik I, Cerny-Reiterer S, Rulicke T, Stefanzl G, Willmann M, et al. Dipeptidylpeptidase IV (CD26) defines leukemic stem cells (LSC) in chronic myeloid leukemia. Blood. 2014;123:3951-62.

29. Andersson EI, Tanahashi T, Sekiguchi N, Gasparini VR, Bortoluzzi S, Kawakami T, et al. High incidence of activating STAT5B mutations in CD4-positive T-cell large granular lymphocyte leukemia. Blood. 2016;128:2465-8.

30. Dufva O, Kankainen M, Kelkka T, Sekiguchi N, Awad SA, Eldfors S, et al. Aggressive natural killer-cell leukemia mutational landscape and drug profiling highlight JAK-STAT signaling as therapeutic target. Nat Commun. 2018;9:1567

31. Kovacic B, Stoiber D, Moriggl R, Weisz E, Ott RG, Kreibich R, et al. STAT1 acts as a tumor promoter for leukemia development. Cancer Cell. 2006;10:77-87.

32. Warsch W, Kollmann K, Eckelhart E, Fajmann S, Cerny-Reiterer S, Hölbl A, et al. High STAT5 levels mediate imatinib resistance and indicate disease progression in chronic myeloid leukemia. Blood. 2011;117:3409-20.

33. Tam WF, Hähnel PS, Schüler A, Lee BH, Okabe R, Zhu N, et al. STAT5 is crucial to maintain leukemic stem cells in acute 
myelogenous leukemias induced by MOZ-TIF2. Cancer Res. 2013;73:373-84.

34. Liu W, Liu X, Yu W-M, Bunting KD, Qu C-K. Critical role of Stat5 in the maintenance of leukemic stem cells in Ptpn11-associated juvenile myelomonocytic leukemia. Blood. 2014;124:818

35. Stoiber D, Kovacic B, Schuster C, Schellack C, Karaghiosoff M, Kreibich R, et al. TYK2 is a key regulator of the surveillance of B lymphoid tumors. J Clin Invest. 2004;114:1650-8.

36. Putz EM, Gotthardt D, Hoermann G, Csiszar A, Wirth S, Berger A, et al. CDK8-Mediated STAT1-S727 Phosphorylation Restrains NK Cell Cytotoxicity and Tumor Surveillance. Cell Rep. 2013;4:437-44.

37. Imada K, Bloom ET, Nakajima H, Horvath-Arcidiacono JA, Udy GB, Davey HW, et al. Stat5b is essential for natural killer cellmediated proliferation and cytolytic activity. J Exp Med. 1998;188:2067-74.

38. Villarino A, Laurence A, Robinson GW, Bonelli M, Dema B, Afzali B, et al. Signal transducer and activator of transcription 5 (STAT5) paralog dose governs $\mathrm{T}$ cell effector and regulatory functions. eLife. 2016;5.e08384

39. Uddin S, Lekmine F, Sassano A, Rui H, Fish, EN, Platanias LC, et al. Role of Stat5 in type I interferon-signaling and transcriptional regulation. Biochem Biophys Res Commun. 2003;308:325-30.

40. Tanabe Y, Nishibori T, Su L, Arduini, RM, Baker DP, David M. Cutting edge: role of STAT1, STAT3, and STAT5 in IFN-alpha beta responses in T lymphocytes. J Immunol. 2005;174:609-13.

41. Gonsky R, Deem RL, Bream J, Young HA, Targan SR. Enhancer role of STAT5 in CD2 activation of IFN-gamma gene expression. J Immunol. 2004;173:6241-7.

42. Wellbrock C, Weisser C, Hassel JC, Fischer P, Becker J, Vetter CS, et al. STAT5 contributes to interferon resistance of melanoma cells. Curr Biol. 2005;15:1629-39.

43. Gough DJ, Messina NL, Clarke CJP, Johnstone RW, Levy DE. Constitutive type I interferon modulates homeostatic balance through tonic signaling. Immunity. 2012;36:166-74.
44. Parker BS, Rautela J, Hertzog PJ. Antitumour actions of interferons: implications for cancer therapy. Nat Rev Cancer. 2016;16:131-44

45. Ren Z, Aerts JL, Vandenplas H, Wang JA, Gorbenko O, Chen JP, et al. Phosphorylated STAT5 regulates p53 expression via BRCA1/BARD1-NPM1 and MDM2. Cell Death Dis. 2016;7: e2560.

46. Mukhopadhyay UK, Cass J, Raptis L, Craig AW, Bourdeau V, Varma S, et al. STAT5A is regulated by DNA damage via the tumor suppressor p53. Cytokine. 2016;82:70-79.

47. Girardot M, Pecquet C, Chachoua I, Van Hees J, Guibert S, Ferrant A, et al. Persistent STAT5 activation in myeloid neoplasms recruits p53 into gene regulation. Oncogene. 2015;34:1323-32.

48. Moser C, Ruemmele P, Gehmert S, Guibert S, Ferrant A, Knoops $\mathrm{L}$, et al. STAT5b as molecular target in pancreatic cancer-inhibition of tumor growth, angiogenesis, and metastases. Neoplasia. 2012;14:915-25.

49. Bernaciak TM, Zareno J, Parsons JT, Silva CM. A novel role for signal transducer and activator of transcription $5 b$ (STAT5b) in beta1-integrin-mediated human breast cancer cell migration. Breast Cancer Res. 2009;11:R52.

50. Najjar I, Grimont A, Martin N, Martin-Lanneree S, Bonnet ML, Guilhot F, et al. Distinct functions of Stat5A and Stat5B in chronic myeloid leukemia (CML): Stat5B is implicated in survival and selfrenewal and Stat5A in imatinib resistance. Blood. 2010;116:1214.

51. Talpaz M, Hehlmann R, Quintás-Cardama A, Mercer J, Cortes J. Re-emergence of interferon- $\alpha$ in the treatment of chronic myeloid leukemia. Leukemia. 2013;27:803-12.

52. Kujawski LA, Talpaz M. The role of interferon-alpha in the treatment of chronic myeloid leukemia. Cytokine Growth Factor Rev. 2007;18:459-71.

53. Kiladjian J-J, Mesa RA, Hoffman R. The renaissance of interferon therapy for the treatment of myeloid malignancies. Blood. 2011;117:4706-15. 